\title{
Application of 5,10,15,20-Tetrakis(4-carboxyphenyl)porphine for Cadmium Preconcentration in Flow-Injection System
}

\author{
Krzysztof KILIAN and Krystyna PyrzyŃSKA ${ }^{\dagger}$ \\ Warsaw University, Department of Chemistry, Pasteura 1, 02-093 Warsaw, Poland
}

\begin{abstract}
The suitability of 5,10,15,20-tetrakis(4-carboxyphenyl)porphine as a complexing agent for the on-line preconcentration of cadmium using an anion exchanger (Amberlite IRA-904) in a microcolumn has been tested. Various parameters which affect complex formation and its sorption, as well as elution into the nebulizer of flame atomic absorption spectrometry (FAAS), were optimized. A $5 \times 10^{-4} \mathrm{~mol}^{-1}$ reagent was on-line mixed with an aqueous sample solution and flowed through the microcolumn for $2 \mathrm{~min}$. The sorbed complexes were then eluted with $2 \mathrm{~mol} \mathrm{l}^{-1}$ of nitric acid into the

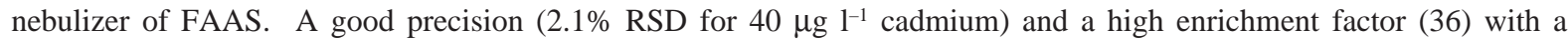
detection limit $(3 \sigma)$ of $1.4 \mu \mathrm{g}^{-1}$ were obtained. The achieved analytical results for a standard reference material (SRM $1643 \mathrm{~d}$ ) were in good agreement with the certified values.
\end{abstract}

(Received December 3, 2001; Accepted February 8, 2002)

\section{Introduction}

The release of cadmium into the environment from mining operations, waste incineration and combustion of coal or oil constitutes a significant pollution problem. Cadmium metabolism and toxicology are of great concern, since this element has accumulation capabilities in several organs of the body, with consequent adverse health effects. ${ }^{1}$

The concentration level of cadmium in some environmental matrices, such as natural water, is fairly low, and very sensitive techniques are required. Electrothermal atomic absorption spectrometry (ETAAS) or inductively coupled plasma mass spectrometry (ICP-MS) usually have sufficient sensitivity to allow cadmium determination in these samples. However, ETAAS measurements are often hindered by severe matrix effects, ${ }^{2}$ and in the ICP-MS method all of the useful isotopes of cadmium are overlapped by various isotopes of MoO molecular ions. ${ }^{3}$ Flame atomic absorption spectrometry (FAAS), which is available in most laboratories, and is normally less subjected to interferences, could also be employed for the determination of cadmium in environmental samples if combined with a suitable preconcentration step. Additionally, a preconcentration system combining flow injection (FI) with on-line enrichment involves less risk of contamination and loss as well as increased sampling frequency and throughput. ${ }^{4}$

Among several preconcentration techniques, interactions based on chelate formation have received considerable attention in recent years due to their simplicity and ability to attain a high enrichment. ${ }^{5,6}$ The complexing agents that have been mostly used for the on-line preconcentration of cadmium are diethyldithiocarbamate $(\text { DDTC })^{7-9}$ and pyrrolidinedithiocarbamate (APDC). ${ }^{10-12}$ The preconcentration of $\mathrm{Cd}(\mathrm{II})$ chelates with 1,10-phenanthroline was carried out using $\mathrm{C}_{60}$ fullerane microcolumn ${ }^{10}$ and $\mathrm{C}_{18}$ sorbent material. ${ }^{13}$ Chelating resins containing phosphonic groups have also been

$\doteqdot$ To whom correspondence should be addressed. investigated concerning the sorption of cadmium. ${ }^{14,15}$

This paper discusses the optimization and application of a flow-injection system for the preconcentration of cadmium. The method is based on the complexation of $\mathrm{Cd}(\mathrm{II})$ with 5,10,15,20-tetrakis(4-carboxyphenyl)porphine (TCPP) and the retention of the formed complex on a microcolumn packed with a macroporous anion-exchange resin. The aim of this work was to develop a rapid and reliable analytical procedure for cadmium determination in natural water samples.

\section{Experimental}

\section{Reagents and materials}

Analytical reagent-grade chemicals were used as well as deionized water from a Milli-Q system. Standard solutions of cadmium were prepared by the appropriate dilution of $1000 \mathrm{mg}$ $1^{-1}$ of a stock solution from Merck. 5,10,15,20-Tetrakis(4carboxyphenyl)porphine (TCPP) from Fluka was used without further purification.

The macroporous anion-exchange resin Amberlite IRA-904 (50 - 100 mesh) from Bio Rad Laboratories was applied to prepare the microcolumn.

\section{Apparatus and procedure}

A Perkin Elmer 3110 atomic absorption spectrometer equipped with a hollow-cathode cadmium lamp and a deuterium background corrector utilised the $\mathrm{Cd} 228.8 \mathrm{~nm}$ line. An air-acetylene flame was adjusted according to the manufacturer's recommendation. Time-resolved absorbance signals of the elution peaks were displayed on the monitor and printed together with the peak height values (evaluation of the spectrometer was operated with a time contact of $1 \mathrm{~s}$ ).

The FI system used, shown schematically in Fig. 1, consisted of an Ismatec MS/4 Reglo peristaltic pump, two Rheodyne RH 5020 low-pressure injection valves and a microcolumn manufactured from a pipette tip (the ends of which were fitted with cotton to retain the sorbent in the tube). The microcolumn 
A)
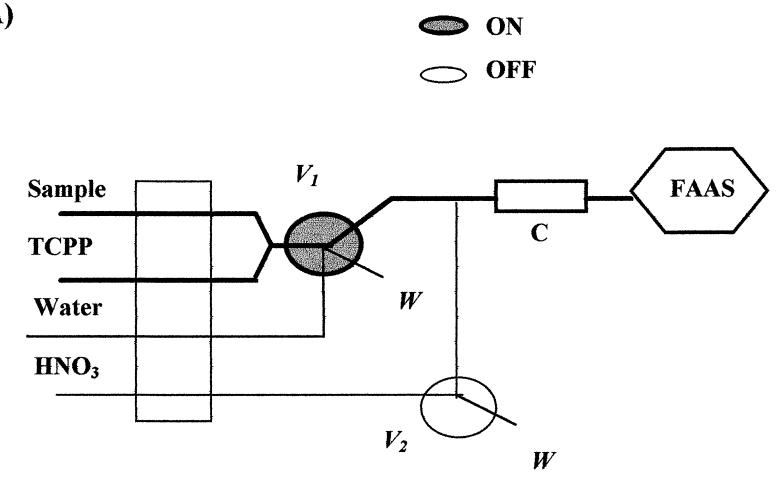

B)

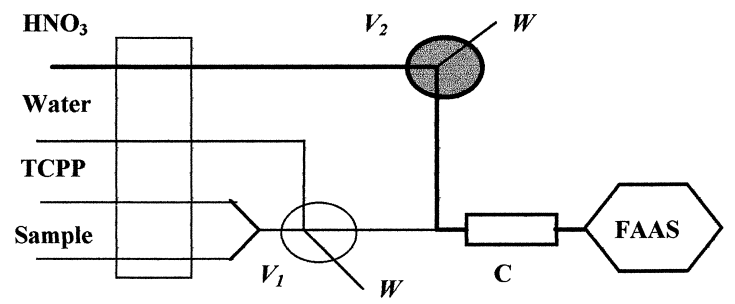

Fig. 1 FI manifold for the on-line preconcentration of $\mathrm{Cd}(\mathrm{II})$. V, multifunctional valves; C, microcolumn; W, waste. (A) Preconcentration step; (B) elution step.

(packed with $200 \mathrm{mg}$ of sorbent) was integrated into the system between the eluent injection valve and the nebulizer of the instrument. It was initially washed with $2 \mathrm{~mol} \mathrm{l}^{-1} \mathrm{HNO}_{3}$ and deionized water before use. PTFE tubes $(0.8 \mathrm{~mm}$ i.d.) were employed for the coils. The flow system was operated in the time-based mode and deionized water served as the carrier stream.

In the preconcentration step, the sample and TCPP solution (at $5 \times 10^{-4} \mathrm{~mol} \mathrm{l}^{-1}$ in $0.05 \mathrm{~mol} \mathrm{l}^{-1}$ borate buffer, $\mathrm{pH} \mathrm{9)}$ were pumped continuously through the manifold at a flow rate of 3.5

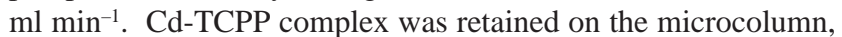
and the sample matrix was sent to the waste system. Then, the first injection valve was switched to its other position and $2 \mathrm{~mol}$ $1^{-1}$ nitric acid was injected by means of a second injection valve in order to release cadmium directly into the nebulizer of the spectrometer. Finally, a blank carrier (deionized water) was passed through the microcolumn for $30 \mathrm{~s}$ in order to condition it for the following sample introduction.

\section{Results and Discussion}

Porphine nucleus are macrocyclic ligands, and metal complexation takes place via four nitrogen atoms. Porphyrins have been mostly used (except in the case of TCPP) as sensitive chromogenic reagents and the stationary phases in HPLC. ${ }^{16}$ $\mathrm{Cd}(\mathrm{II})$ reacted with carboxyphenyl porphyrin to form a $1: 1$ complex with the maximum at the Soret band at $431 \mathrm{~nm}$, whereas at the Q-band it showed the absorption peaks at $570 \mathrm{~nm}$ and $612 \mathrm{~nm}$ (Fig. 2). The carboxylic groups allow the retention of the Cd-TCCP complex as well as a ligand alone on a microcolumn packed with anion-exchange resin.

The application of carboxyphenyl porphyrin as a complexing

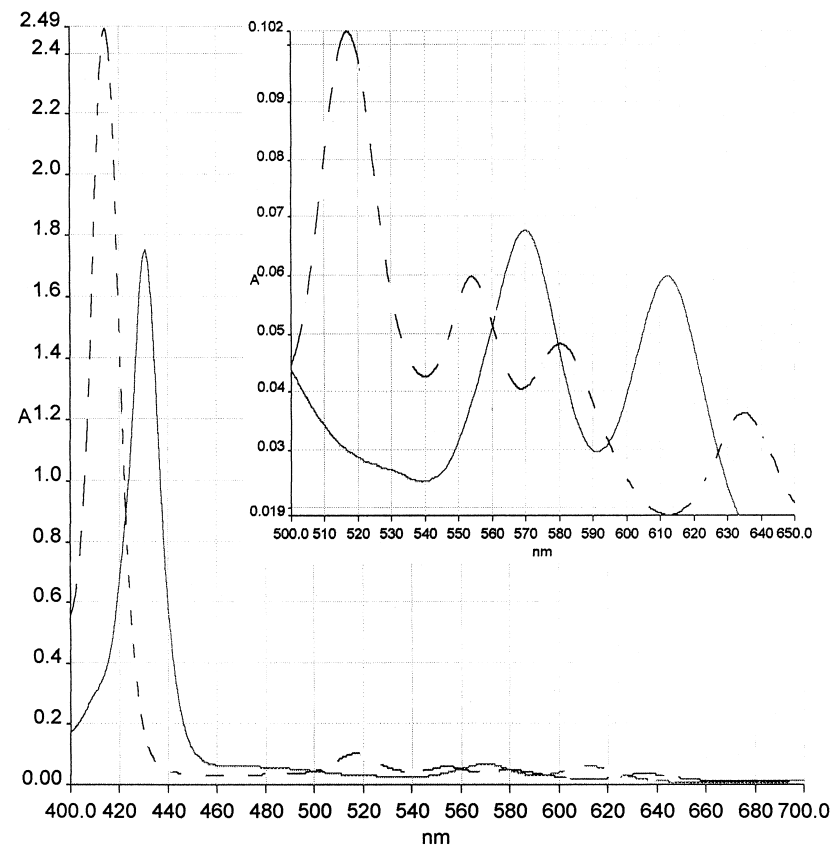

Fig. 2 Absorption spectra of Cd-TCPP complex (solid line) and TCPP ligand (dotted line).

reagent for the solid-phase extraction of $\mathrm{Cu}(\mathrm{II}), \mathrm{Ni}(\mathrm{II}), \mathrm{Cd}(\mathrm{II})$, $\mathrm{Co}$ (II) and $\mathrm{Pb}$ (II) was investigated under static conditions. ${ }^{17}$ It was found that complexation of these metal ions in solution followed by retention of the formed chelates gave a higher recovery compared with the results obtained for TCPP-modified sorbents. Probably, porphyrin immobilized on a sorbent could be sterically unfavorable to the chelation of metal ions, thus reducing the amount of the analytes complexed. Thus, by taking advantage of the complexation reaction in solution, a systematic study was undertaken for determining cadmium after on-line enrichment on a microcolumn. Different parameters which affect complex formation and its subsequent sorption and elution into the nebulizer of FAAS were optimized using the univariate method.

\section{Chemical and flow optimization}

The flow system presented in Fig. 1 was studied in relation to both the chemical and flow variables in order to obtain the best analytical conditions. The $\mathrm{pH}$ of the sample solution was chosen based of previous studies ${ }^{17}$ when cadmium recovery increased with increasing $\mathrm{pH}$. An adjustment of the sample $\mathrm{pH}$ to 9 could be achieved by using a TCPP solution with a 0.05 mol $1^{-1}$ borate buffer. For spectrophotometric determination of Cd(II) with other water-soluble porphyrins, borate buffer was also used, e.g. with 5,10,15,20-tetrakis(4-sulfonatophenyl)porphine $^{18}$ at $\mathrm{pH}$ 8.8. Moreover, borate buffer (at $\mathrm{pH}$ 9.2) was applied for TCPP chelate formation with some metal ions using micellar electrokinetic capillary chromatography. ${ }^{19}$

The effect of the porphyrin concentration (in $0.05 \mathrm{~mol} \mathrm{l}^{-1}$ borate buffer) was investigated. The results showed that the recovery of $0.5 \mu \mathrm{g}$ of cadmium increased up to $10^{-5} \mathrm{~mol}^{-1}$ of TCPP, since the equilibrium was shifted toward complex formation. The variation in the absorbance signal along with a further increase in the ligand concentration was negligible. Thus, a $5 \times 10^{-4} \mathrm{~mol} \mathrm{l}^{-1}$ reagent solution was selected.

Changes in the flow rate of the sample $(5 \mathrm{ml})$ between 2 and $4.5 \mathrm{ml} \mathrm{min}{ }^{-1}$ resulted in very small variations in the cadmium 


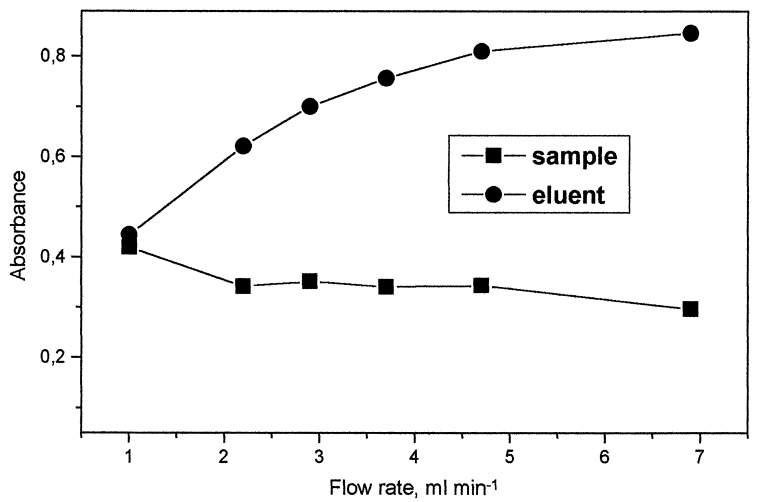

Fig. 3 Effect of sample loading and the eluent flow rates on the absorbance of $100 \mu \mathrm{g} \mathrm{l}^{-1}$ cadmium.

recovery (in these experiments the flow rate during the elution step was $1 \mathrm{ml} \mathrm{min}^{-1}$ ). It means that the analyte sorption kinetics was fast. At higher flow rates, the analytical signal decreased owing to the short residence time of the sample, which resulted in an incomplete retention of cadmium. (Fig. 3). To achieve high efficiency, a flow rate of $3.5 \mathrm{ml} \mathrm{min}^{-1}$ for sample loading was proposed. The elution rate is equally important for good precision and better sensitivity. The eluent flow rate was varied from $1 \mathrm{ml} \mathrm{min}^{-1}$ to $6.9 \mathrm{ml} \mathrm{min}{ }^{-1}$ (Fig. 3). The absorbance increased in a regular manner along with an increase of in the flow rate up to the natural aspiration rate of the nebulizer $(6.8$ $\mathrm{ml} \mathrm{min}^{-1}$ ), which also suggests fast kinetics for the elution process.

The elution of preconcentrated cadmium was achieved by first breaking the metal-chelate bonds and then applying nitric acid solution at a concentration of $2 \mathrm{~mol} \mathrm{l}^{-1}$. The minimum volume of $\mathrm{HNO}_{3}$ necessary to displace the complex from an Amberlite IRA-904 microcolumn (200 mg) was evaluated to be $500 \mu \mathrm{l}$. It was found that when two consecutive injections of $\mathrm{HNO}_{3}$ solution were applied, no change in the absorbance was observed after the second injection, indicating the complete elution of cadmium by the first aliquot of the eluent. After the elution step, a sorbent needed to be prepared for passage of the following sample. The carrier (deionized water) was pumped through the microcolumn for different times and a time of $30 \mathrm{~s}$ after the appearance of a signal was found to be optimum for sorbent conditioning.

\section{Analytical performance}

A linear correlation between the absorbance and the cadmium concentration was obtained up to $100 \mu \mathrm{g}^{-1}$ of $\mathrm{Cd}(\mathrm{II})$. The detection limit based on three-times standard deviation of the peak absorbance was $1.4 \mu \mathrm{g} \mathrm{l}^{-1}$ using a preconcentration time of $2 \mathrm{~min}$. The precision obtained at the $40 \mu \mathrm{g} \mathrm{l^{-1 }}$ level $(n=10)$ was $2.1 \%$, expressed as RSD.

The experimental enrichment factor (EF) was calculated as the ratio of the slopes of the calibration graphs obtained with and without preconcentration. In our method, $\mathrm{EF}=36$ for a 2 min sample loading time. However, the efficiency of preconcentration essentially depends on the time taken for the sample solution to pass through a microcolumn. The application of longer loading time improves the enrichment, but simultaneously leads to a decrease in a sample rate. Hence, it seems to be very appropriate to use a concentration efficiency (CE) for comparing of various flow-injection systems with a preconcentration step. $\mathrm{CE}$ is the product of the enrichment factor and the sampling rate. Using our method, a sample
Table 1 Determination of cadmium in natural water samples $\left(\mu \mathrm{g} \mathrm{1^{-1 } )}\right.$

\begin{tabular}{lcccc}
\hline \multirow{2}{*}{ Sample } & $\begin{array}{c}\text { Certified } \\
\text { value }\end{array}$ & \multicolumn{2}{c}{ Determined value } & Recovery, ${ }^{a}$ \\
& FI-FAAS & ETAAS & $\%$ \\
\hline Mineral water & - & $20.2 \pm 2.5$ & - & $101 \pm 2.5$ \\
SRM 1643d & $6.5 \pm 0.4$ & $6.7 \pm 0.4$ & - & - \\
Lake water & - & $13.2 \pm 1.0$ & $11.2 \pm 0.8$ & - \\
\hline
\end{tabular}

a. After spiking the sample with $20 \mu \mathrm{g}^{-1} \mathrm{Cd}$.

throughput of $20 \mathrm{~h}^{-1}$ was obtained.

Upon comparing these results with those mentioned in previous published papers concerning on-line preconcentration coupled to flame AAS detection, a lower detection limit was reported for DDTC complexes sorbed on $\mathrm{C}_{18}$ columns ${ }^{7,8}$ and for poly(aminophosphorous acid) chelating resin. ${ }^{15}$ However, the value of $\mathrm{EF}$ achieved in the present work was much higher, which demonstrates the efficiency of this approach. In the work of Xu et al. ${ }^{12}$ although the performance of the enrichment of $\mathrm{Cd}$ APDC complex gave a detection limit of $0.5 \mathrm{ng} \mathrm{l}^{-1}$, more sensitive ETAAS detection method was applied.

The effect of potential interferences occurring in natural water samples on the determination of cadmium was investigated using the optimized FI system. Different amounts of metal ions were added individually to a $100 \mu \mathrm{g}^{-1} \mathrm{Cd}$ solution and passed for $2 \mathrm{~min}$ through columns containing $200 \mathrm{mg}$ of Amberlite IRA-904. Elution was performed using $2 \mathrm{~mol} \mathrm{l}^{-1} \mathrm{HNO}_{3}$. The obtained results showed that the presence of calcium and magnesium up to the $10 \mathrm{mg} \mathrm{l}^{-1}$ concentration level did not significantly affect the determination of cadmium. The recovery was in the range of $97-104 \%$. Metal ions such Ni(II), $\mathrm{Pb}$ (II) and $\mathrm{Co}$ (II) could be tolerated up to $1 \mathrm{mg} \mathrm{l}^{-1}$. $\mathrm{Cu}$ (II) could be tolerated up to $0.5 \mathrm{mg} \mathrm{l}^{-1}$, but interfered at higher concentrations, and thus lowering the absorbance signal (20\%). The reason for this may have been that copper might have formed a complex with TCPP and competed in the sorption process on the microcolumn. Although Fe(III) did not interfere up to $0.1 \mathrm{mg} \mathrm{l}^{-1}$, at a higher concentration a lower recovery (78\%) was obtained. An attempt to decrease the interferences from iron by increasing the amount of resin up to $500 \mathrm{mg}$ at the expense of lowering the enrichment factor was not successful. Also, the addition of fluoride and salicylic acid to the sample solution prior to the preconcentration step resulted in a similar incomplete recovery of cadmium. Thus, the proposed method could be sufficient for applications to water samples, except for those which are heavily polluted with $\mathrm{Fe}(\mathrm{III})$.

\section{Application to natural water samples}

The developed method for the determination of cadmium using an on-line preconcentration system and flame AAS detection was examined for several natural water samples (Table 1). The experiments were carried out using a microcolumn packed with $200 \mathrm{mg}$ of an anion-exchange resin (Amberlite IRA-904). The recoveries for spiked addition to a mineral water sample (20 $\mu \mathrm{g} \mathrm{l}^{-1}$ of cadmium) gave a mean result of $(101 \pm 2.5) \%(n=3)$.

In order to study the accuracy of the proposed method, SRM Trace Elements in Fresh Water with a cadmium content of 6.10 - $6.84 \mu \mathrm{g}^{-1}$ was analyzed. A mean value $(95 \%$ confidence limit for six measurements) of $6.7 \pm 0.4 \mu \mathrm{g} \mathrm{l^{-1 }}$ was obtained. As can be seen, there is a good agreement between the experimental and certified values.

The practical feasibility of the proposed method for the determination of cadmium was tested on natural water sample 
collected from (small) Lake Czerniakowskie in the southeast area of Warsaw City. After filtration using $0.45 \mu \mathrm{m}$ filter, four replicates were performed by combining preconcentration in the flow injection system with FAAS detection. The cadmium content in that sample was also determined by the ETAAS method (Table 1). A comparison of both methods gives an indication of the reliability of the FI on-line preconcentration procedure. Our methodology was shown to be an effective approach for improving the sensitivity of flame AAS cadmium determination in natural water samples.

\section{References}

1. K. Robards and P. Worsfold, Analyst, 1991, 116, 549.

2. S. Ashan, S. Kaneco, K. Ohta, T. Mizuno, and Y. Taniguchi, Talanta, 1999, 48, 63.

3. T.-J. Hwang and S.-J. Jiang, J. Anal. At. Spectrom., 1997, 12,579 .

4. Z. L. Fang, Anal. Chim. Acta, 1999, 400, 233.

5. K. Terada, Anal. Sci., 1991, 7, 187.

6. M. Torre and L. Marina, Crit. Rev. Anal. Chem., 1994, 24, 327.

7. Z. L. Fang, T. Guo, and B. Weltz, Talanta, 1991, 38, 613.
8. C. G. Bruhn, C. Vilches, and H. J. Cid, Bol. Soc. Chil. Quim., 1999, 44, 321.

9. A. Uzun, M. Soylak, and L. Elç, Talanta, 2001, 54, 197.

10. Y. P. De Pena, M. Gallego, and M. Valcarcel, J. Anal. At. Spectrom., 1997, 12, 453.

11. D. Colbert, K. S. Johnson, and K. H. Coale, Anal. Chim Acta, 1998, 377, 255.

12. Z.-R. Xu, H.-Y. Pan, S.-K. Xu, and Z. L. Fang, Spectrochim. Acta, 2000, 55B, 213.

13. A. Ali, X. Yin, H. Shen, Y. Ye, and X. Gu, Anal. Chim. Acta, 1999, 392, 283.

14. N. Kabay, M. Demircioglu, H. Ekinci, M. Yüsel, M. Saglam, M. Akçy, and M. Streat, Ind. Eng. Chem. Res., 1998, 37, 2541.

15. M. F. Enriquez-Dominguez, M. C. Yebra-Biurrun, and M. P. Bermejo-Barrera, Analyst, 1998, 123, 105.

16. M. Biesaga, K. Pyrzyńska, and M. Trojanowicz, Talanta, 2000, 51, 209.

17. K. Kilian and K. Pyrzyńska, Fresenius J. Anal. Chem., 2001, 371, 1076.

18. S. Igarashi, T. Aihara, and T. Yotsuyanagi, Anal. Chim. Acta, 1996, 323, 63.

19. T. Saitoh, H. Hoshino, and T. Yotsuyanagi, Anal. Sci., 1991, 7, 495 . 